\title{
Assessing Potential Acidification of Marine Archaeological Wood Based on Concentration of Sulfur Species
}

\author{
Sara Goldman \\ Office of Science, Science Undergraduate Laboratory Internship (SULI) \\ University of Colorado at Colorado Springs \\ Stanford Synchrotron Radiation Lightsource \\ Stanford, CA
}

August 20, 2010

Prepared in partial fulfillment of the requirements of the Office of Science, Department of

Energy's Science Undergraduate Laboratory Internship under the direction of Dr. Apurva Mehta, Stanford Synchrotron Radiation Lightsource.

Participant:

Signature

Research Advisor:

Signature 


\section{TABLE OF CONTENTS}

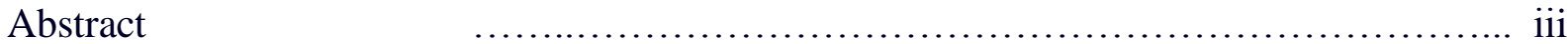

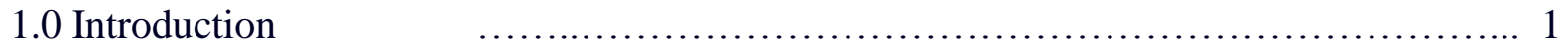

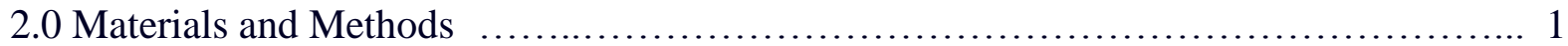

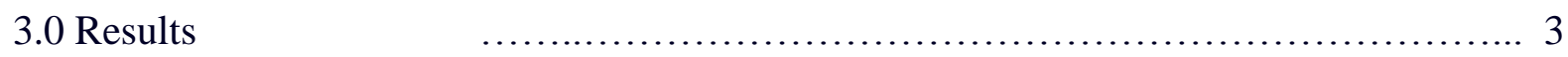

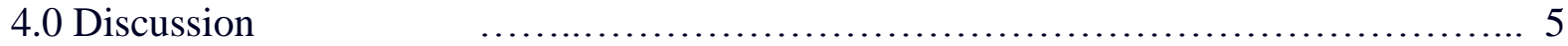



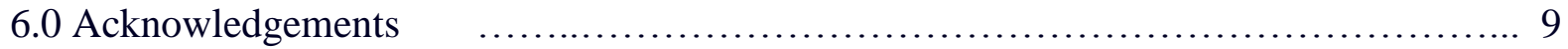

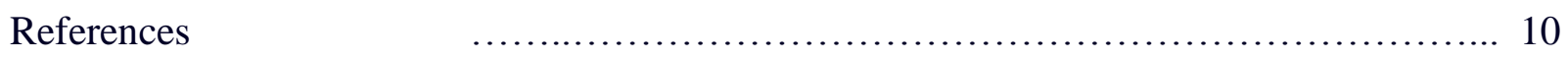






\begin{abstract}
Assessing Potential Acidification of Marine Archaeological Wood Based on Concentration of Sulfur Species. SARA M. GOLDMAN (University of Colorado at Colorado Springs, CO 80918) APURVA MEHTA (Stanford Synchrotron Radiation Lightsource, Menlo Park, CA 94025)
\end{abstract}

The presence of sulfur in marine archaeological wood presents a challenge to conservation. Upon exposure to oxygen, sulfur compounds in waterlogged wooden artifacts are being oxidized, producing sulfuric acid. This speeds the degradation of the wood, potentially damaging specimens beyond repair. Sulfur K-edge x-ray absorption spectroscopy was used to identify the species of sulfur present in samples from the timbers of the Mary Rose, a preserved $16^{\text {th }}$ century warship known to undergo degradation through acidification. The results presented here show that sulfur content varied significantly on a local scale. Only certain species of sulfur have the potential to produce sulfuric acid by contact with oxygen and seawater in situ, such as iron sulfides and elemental sulfur. Organic sulfurs, such as the amino acids cysteine and methionine, may produce acid but are integral parts of the wood's structure and may not be released from the organic matrix. The sulfur species contained in the sample reflect the exposure to oxygen while submerged, and this exposure can differ greatly over time and position. A better understanding of the species' pathway to acidifications required, along with its location, in order to suggest a more customized and effective preservation strategy. 


\subsection{INTRODUCTION}

Waterlogged archaeological wood, frequently in the form of shipwrecks, is being excavated for historical purposes in many countries around the world. Even after extensive efforts towards preservation, scientists are discovering that accumulation of sulfate salts results in acidic conditions on the surfaces of the artifacts. Sulfuric acid degrades structural fibers in the wood by acid hydrolysis of cellulose, accelerating the decomposition of the ship timbers [1]. Determining the sulfur content of waterlogged wood is now of great importance in maritime archaeology. Artifact preservation is often more time consuming and expensive than the original excavation; but it is key to the availability of objects for future study as well as maintaining the integrity of historical data and preserving the value of museum pieces [2].

Sulfur occurs in a wide number of oxidation states from -2 to +6 , and appears in numerous organic and inorganic compounds in nature. However, it is a very minor component of wood. Sulfur K-edge x-ray absorption spectroscopy (XAS) is a valuable technique because it has the ability to detect very low concentrations of sulfur in the specimen. XAS is also sensitive to differences in oxidation states, as well as long and short range order in molecules.

\subsection{MATERIALS AND METHODS}

\subsection{Sample Preparation}

The sample of waterlogged archaeological wood used in the S K-edge XAS study was from the Mary Rose, currently in Portsmouth, England. The piece was cut from the oak stem post, which was excavated in 2003, and had not been treated with any preservation chemicals or any conservation methods other than drying. The sample was approximately $3 \mathrm{~cm}$ by $4 \mathrm{~cm}$ by $1 / 2$ $\mathrm{cm}$. Fifteen spectra were collected at different locations on the sample piece. 


\subsection{S K-edge XAS Data Collection}

Sulfur K-edge X-ray absorption spectra were collected on a 20-pole 2.0 Tesla wiggler unfocussed beamline 4-3 at the Stanford Synchrotron Radiation Lightsource (SSRL) under standard ring operating condition of $3 \mathrm{GeV}$ and $\sim 200 \mathrm{~mA}$ ring current. X-ray energy was varied using a $\mathrm{Si}(111)$ double-crystal monochrometer with a non-fixed exit slit. Other upstream optics included a Ni-coated vertically collimating and harmonic rejection mirror. The sample chamber contained a helium atmosphere. The area of the X-ray beam was $1 \mathrm{~mm}$ by $2 \mathrm{~mm}$. The sample was stored and handled at room temperature. The emitted X-ray fluorescence was measured at an angle of $0^{\circ}$ using a Lytle detector. Thin double-stick sulfur-free Mylar tape was used to affix the sample piece to the sample holder. Energy calibration was achieved using $\mathrm{Na}_{2} \mathrm{~S}_{2} \mathrm{O}_{3} \cdot 5 \mathrm{H}_{2} \mathrm{O}$ as the calibrant, which was run before and after sample scans. The first peak of the $\mathrm{Na}_{2} \mathrm{~S}_{2} \mathrm{O}_{3} \cdot 5 \mathrm{H}_{2} \mathrm{O}$ spectrum was fixed at $2472.02 \mathrm{eV}$ for calibration purposes [3].

S K-edge XAS data on reference compounds used in this study were previously measured on beamline 4-3 by Dr. Ritimukta Sarangi.

\subsection{Data Analysis}

The data were individually viewed in Sixpack, and any faulty or incomplete scans were removed [4]. The scans were calibrated and averaged in EXAFSPAK [5]. A second-order polynomial was fit to the pre-edge region and subtracted from the entire spectra as background. The data were normalized using the Pyspline program by subtracting a cubic spline and assigning the edge jump to 1.0 [6]. The area under the pre-edge peaks was fit using IFEFFIT in Sixpack, as well as the EDG_FIT subroutine in EXAFSPAK [7].

The absorption edge jump on XAS spectra corresponds to the total amount of the element present. It is determined by assigning a linear fit to the original pre-edge and post-edge data and calculating the distance between them (Figure 1). The edge jump of the data sets collected on different areas on the wood sample was calculated with Sixpack. 
Due to the thickness of the sample $( \pm 1 / 2 \mathrm{~cm})$, the resulting spectra were observed to be self-absorbed. Self-absorption correction was achieved using the FLUO program assuming infinite thickness [8].

\subsection{RESULTS}

The edge jumps calculated from the XAS spectra fluctuated from a low of 0.1915 to a high of 0.6897 , indicating that the total sulfur content varied by up to three times on a local level (Table 1).

Although the spectra varied in total sulfur amount and species, two prominent peaks were observed in all of them (Figure 2). The first peak occurred at $2472.96 \mathrm{eV}$. The second larger peak occurred at $2482.60 \mathrm{eV}$.

Data were fitted with spectra using a library of sulfur reference compounds (Figure 3). Multiple fitting combinations were attempted in order to achieve the most accurate fit. The cysteine $\left(\mathrm{C}_{3} \mathrm{H}_{7} \mathrm{NO}_{2} \mathrm{~S}\right)$ and methionine $\left(\mathrm{C}_{5} \mathrm{H}_{11} \mathrm{NO}_{2} \mathrm{~S}\right)$ references produced similar results, and could be used interchangeably. Methionine was selected to act individually rather than including both references. A minor but quantifiable feature appeared between the first and second peak on all fifteen spectra (Figure 2). The sulfoxide reference was adjusted by $-0.25 \mathrm{eV}$ in order to better fit this area. This suggests that either the sulfoxide reference was slightly shifted, or an unidentified alternative compound with an oxidation state very similar to sulfoxide was present in the sample.

After eliminating reference compounds that did not appear in sufficient amounts (less than $1 / 100^{\text {th }}$ of a percent), the samples were fit with five primary components: methionine $\left(\mathrm{C}_{5} \mathrm{H}_{11} \mathrm{NO}_{2} \mathrm{~S}\right)$, sulfoxide ( $\mathrm{R}-\mathrm{S}(=\mathrm{O})-\mathrm{R}^{\prime}$, adjusted), sulfonate $\left(\mathrm{RSO}_{2} \mathrm{O}^{-}\right)$, elemental sulfur $\left(\mathrm{S}_{8}\right)$, and sulfate $\left(\mathrm{SO}_{4}{ }^{2-}\right)$. The fit fractions were calculated to be within 1-2\% standard deviation. Total sums and R-values (the scaled error in the fit) were recorded (Table 1). 
We observed the sum of the component fit fractions did not total to one (100\%) for any of the samples. This difference could partially fall within standard deviation, but it is more likely that the sulfate content of the samples was underestimated due to self-absorption. Requiring the fit fractions to sum to one $(100 \%)$ in the Sixpack program did not substantially alter the fit percentages, but did increase the error (R-value). It was decided that the analysis would continue without forcing the sum to one to maintain minimal error. It was assumed that the sulfate content was underestimated and the self-absorption correction performed was not entirely sufficient.

The fit data were normalized by multiplying the edge jump (total sulfur) by the fit fraction to get the species amount proportional to the total amount of sulfur present. The first peak at $2472.96 \mathrm{eV}$ is composed of elemental sulfur and methionine/cysteine. The second peak at $2482.60 \mathrm{eV}$ is composed primarily of sulfate, and to a lesser extent, sulfonate (Table 2). The features beyond the peak at $2482 \mathrm{eV}$ indicate the presence of an unidentified ordered sulfate (Figure 2). 


\subsection{DISCUSSION}

The sample piece did not receive excessive handling or any conservation chemicals after excavation in 2003. Because of this, we assumed that the components of the sample had not changed extensively in the intervening years, and represented the contents as if the piece had been newly salvaged.

The fit identified five components, discussed here in order of smallest average fit fraction to largest:

\subsection{Sulfonate}

Sulfonate is the salt of sulfonic acid, which is similar to sulfuric acid in structure. Sulfonic acid can be produced through the slow oxidation of organic sulfur (methionine/cysteine) with prolonged exposure to $\mathrm{O}_{2}$ and water. The surviving timbers of the Mary Rose were embedded in clay and buried with silt, resting in an anaerobic environment in situ [9]. The presence of sulfonate suggests that during its 450 year burial period our sample must have come into contact with dissolved oxygen for an extended period of time. The gradual formation of sulfonate from organic compounds suggests that it is a natural consequence of wood spending a very lengthy time in contact with $\mathrm{O}_{2}$ and water, and does not represent an immediate threat to the conservation of the wood. Our component analysis shows that thirteen of the fifteen samples contain small amounts of sulfonate, and the amount does not change greatly based on the total sulfur content.

\subsection{Sulfoxide (adjusted)}

Sulfoxides are oxidized sulfides, but sulfides to not naturally occur in oak. This suggests that sulfoxides are an indicator of an external source of sulfide. Previous studies have identified the activity of anaerobic bacteria in the wood [10]. The bacterial breakdown of organic matter produces hydrogen sulfide $\left(\mathrm{H}_{2} \mathrm{~S}\right)$. The presence of sulfoxides suggests that the ship's environment was either an ideal balance of sufficiently low oxygen to accommodate anaerobic 
bacteria and enough oxygen to oxidize the $\mathrm{H}_{2} \mathrm{~S}$ they produced; or some event occurred beneath the ocean to expose the area to more aerobic conditions. It is reasonable to suggest that a current of sufficient strength could change the silt coverage and thus the wood's exposure to dissolved oxygen. This process of burial and exposure could have happened many times over 450 years under water.

\subsection{Methionine/cysteine}

Sulfur occurs naturally in wood. Trees get the sulfur they require from the soil they grow in by taking up inorganic sulfate, reducing it, and incorporating it into amino acids such as methionine or cysteine [11]. The intensity of the organic sulfur methionine/cysteine peak varied 2.7 times between the least intense to the most intense spectrum. We observed that the intensity of XAS features was sensitive to the concentration of the sulfur species. The variation of the peak intensities for methionine/cysteine would depend on the cell structure of the wood and the underwater exposure it received. The sample with the largest amount of methionine/cysteine made up less than one fifth of its total sulfur content. We observed that the sulfurs in the amino acids were a minor component and did not fluctuate greatly based on the total sulfur content.

\subsection{Elemental Sulfur}

Inorganic elemental sulfur was present in all fifteen spectra as the primary component of the first peak observed at $2472.96 \mathrm{eV}$. Elemental sulfur does not occur naturally in wood. The presence of elemental sulfur in the sample is primarily attributed to the $\mathrm{H}_{2} \mathrm{~S}$-producing anaerobic bacteria. $\mathrm{H}_{2} \mathrm{~S}$ can react with free sulfates in the water to produce elemental sulfur. Elemental sulfur combined with seawater and oxygen can produce sulfuric acid. The fact that $S_{8}$ is a required component of the fit indicates that it was lacking sufficient oxygen while under water to totally acidify. Rather, enough $\mathrm{O}_{2}$ was present in the water to contribute to the formation of elemental sulfur, but not enough to oxidize it entirely. 


\subsection{Sulfate}

Sulfate is the salt of sulfuric acid, and appears as the primary component of the total sulfur in all the samples. In fact, the increase in total sulfur content was primarily a result of increasing sulfate in the sample (Figure 4). Wood does not naturally contain sulfate, all of it had to come from an external source.

There are several pathways to producing sulfate, each beginning with the presence of the hydrogen sulfide produced by anaerobic bacteria. Hydrogen sulfide can form sulfuric acid by reacting with oxygen and seawater:

$$
\mathrm{H}_{2} \mathrm{~S}+\mathrm{O}_{2}+2 \mathrm{H}_{2} \mathrm{O} \rightarrow 6 \mathrm{H}^{+}+\mathrm{SO}_{4}^{2-}
$$

Additionally, $\mathrm{H}_{2} \mathrm{~S}$ can form elemental sulfur if $\mathrm{SO}_{4}{ }^{2-}$ is present in the water, and that $\mathrm{S}_{8}$ can form more sulfuric acid with water and oxygen.

Previous studies have identified iron sulfides as a potential sulfur component in the wood [12]. The ship contained thousands of iron nails and fixtures, which over time would likely release ferric ions into the water. Hydrogen sulfide reacting with these ferric ions can produce iron sulfides such as pyrite $\left(\mathrm{FeS}_{2}\right)$ and pyrrhotite $(\mathrm{FeS})$. These iron sulfides can produce sulfuric acid upon contact with air and seawater:

$$
2 \mathrm{FeS}_{2}+7 \mathrm{O}_{2}+2 \mathrm{H}_{2} \mathrm{O} \rightarrow 2 \mathrm{Fe}^{2+}+4 \mathrm{SO}_{4}{ }^{2-}+\mathrm{H}^{+}
$$

Iron sulfides can also form elemental sulfur and iron hydroxide if acid and other metal oxides are already present:

$$
\mathrm{FeS}+1.5 \mathrm{MnO}_{2}+3 \mathrm{H}^{+} \rightarrow \mathrm{Fe}(\mathrm{OH})_{3}+\mathrm{S}^{0}+1.5 \mathrm{Mn}^{2+}
$$

Our sample spectra could not establish the presence of any form of iron sulfides. This indicates three possibilities. First, our sample did not have sufficient access to ferric ions and thus never contained iron oxides; second, if iron oxides formed, there was enough $\mathrm{O}_{2}$ present to oxidize them immediately (either underwater or upon excavation); and third, the $\mathrm{H}_{2} \mathrm{~S}$ reacted with any $\mathrm{O}_{2}$ present to form sulfuric acid, rather than the $\mathrm{H}_{2} \mathrm{~S}$ reacting with ferric ions to form iron sulfides. 
Considering the extensive time under water and varied exposure to oxygen, combinations of these scenarios could occur as well.

The features on the XAS spectra beyond the second peak at $2482.60 \mathrm{eV}$ indicate the presence of an unidentified ordered sulfate (Figure 2). The more level (and less abundant) features beyond the second peak indicate a disordered free sulfate. The presence of a large amount of bound sulfates indicates that ordered insoluble metal sulfates have formed, meaning direct contact with metal ions has occurred. There is a small likelihood that the free cations were in the container holding the sample after excavation, or perhaps transferred during handling. The more likely explanation is that the sulfates came into contact with metal ions while still submerged. Seawater is known to contain many dissolved salts, and the most probable cations are sodium, magnesium, calcium, potassium, and strontium.

\subsection{CONCLUSIONS}

All of the sulfur species capable of becoming sulfuric acid upon contact with air and seawater were introduced as a result of the activities of anaerobic bacteria. The sulfur-bearing amino acids which naturally occur in the wood have the capability of producing minor amounts of sulfonic acid rather than sulfuric acid. However, all of these reactions hinge on the presence of oxygen.

In order for sulfate, sulfonate, sulfoxide, and elemental sulfur to be formed in our sample, oxygen had to be present over an extended period of time while submerged. A method to determine the oxygen exposure under water could assist in identifying how much sulfur is present with the immanent potential to acidify upon excavation.

Further XAS data analysis and comparison to reference compounds is required to identify the cation of the ordered sulfate. This would help us determine if the sulfates are reacting primarily under water, or if the sample is being contaminated during excavation and handling. 
Also, if it is determined that the sulfate produced while under water has completely reacted while submerged, then any additional free sulfates identified later would have been formed after excavation by contacting atmospheric oxygen.

Additional references are required to ascertain whether or not sulfoxide is actually present or if a similarly structured compound is there instead.

Even though self-absorption correction was applied, it did not sufficiently adjust the sulfate amount. Further XAS spectra should be taken focusing on the issue of self-absorption in order to reduce the error in reference fitting.

\subsection{ACKNOWLEDGEMENTS}

I would like to thank Dr. Apurva Mehta for mentoring me on this project, and for dispensing exceptional advice and encouragement. I would also like to thank Dr. Ritimukta Sarangi for her generous support and guidance, and for contributing the additional S K-edge references used. Thank you to Dr. Eleanor Schofield, for the providing the sample and sharing beam time. Additionally, thanks to Dr. Steven Rock for his direction of the SULI program at SLAC. This research was funded by the U.S. Department of Energy, and the Stanford Synchrotron Radiation Lightsource. 


\section{REFERENCES}

[1] J. Gillon, " Marine archaeology: Acid attack," Nature, vol. 415, no. 21 Feb, pp. 847, 2002.

[2] D.L. Hamilton, Methods of Conserving Archaeological Material from Underwater Sites, 1 ed. , College Station, TX: Texas A\&M University, 1999.

[3] R. Sarangi, J.T. York, M.E. Helton, K. Fujisawa, K.D. Karlin, W.B. Tolman, K.O. Hodgson, B. Hedman, E.I. Solomon, " X-Ray absorption spectroscopic and theoretical studies on (L)2[Cu2(S2)n]2+ complexes: Disulfide versus disulfide(1-) bonding," Journal of the American Chemical Society, vol. 130, pp. 676-686, 2008.

[4] S. Webb, Sixpack, version 0.67, 2010.

[5] G.N. George, EXAFSPAK and EDG_FIT, 2001.

[6] A. Tenderholt, PySpline: A program of processing XAS data, version 1.1, 2006.

[7] M. Newville, IFEFFIT, version 1.2.10, 2010.

[8] D. Haskel, FLUO, 1999.

[9] M. Sandström, F. Jalilehvand, E. Damian, Y. Fors, U. Gelius, M. Jones, M. Salome, " Sulfur accumulation in the timbers of King Henry VIII's warship Mary Rose: A pathway in the sulfur cycle of conservation concern," PNAS, Proceedings of the National Academy of Sciences, vol. 102, no. 40, pp. 14165-14170, 2005.

[10] K.M. Wetherall, R.M. Moss, A.M. Jones, A.D. Smith, T. Skinner, K.M. Pickup, S.W. Goatham, A.V. Chadwick, R.J. Newport, " Sulfur and iron speciation in recently recovered timbers of the Mary Rose revealed via X-ray absorption spectroscopy," Journal of Archaeological Science, vol. 35, pp. 1317-1328, 2008.

[11] S. Kopriva, T. Hartmann, G. Massaro, P. Hönicke, H. Rennenberg, " Regulation of sulfate assimilation by nitrogen and sulfur nutrition in poplar trees ," Trees - Structure and Function, vol. 18, no. 3, May, pp. 320-326, 2004. 
[12] M Sandström, F. Jalilehvand, I. Persson, U. Gelius, P. Frank, I. Hall-Roth, " Deterioration of the seventeenth-century warship Vasa by internal formation of sulphuric acid," Nature, vol. 415, no. 21 Feb, pp. 893-897, 2002.

[13] B.B. Jørgensen, D.C. Nelson, " Sulfide Oxidation in marine sediments: Geochemistry meets microbiology," Geological Society of America Special Papers, vol. 379, pp. 63-81, 2004. 


\section{FIGURES}

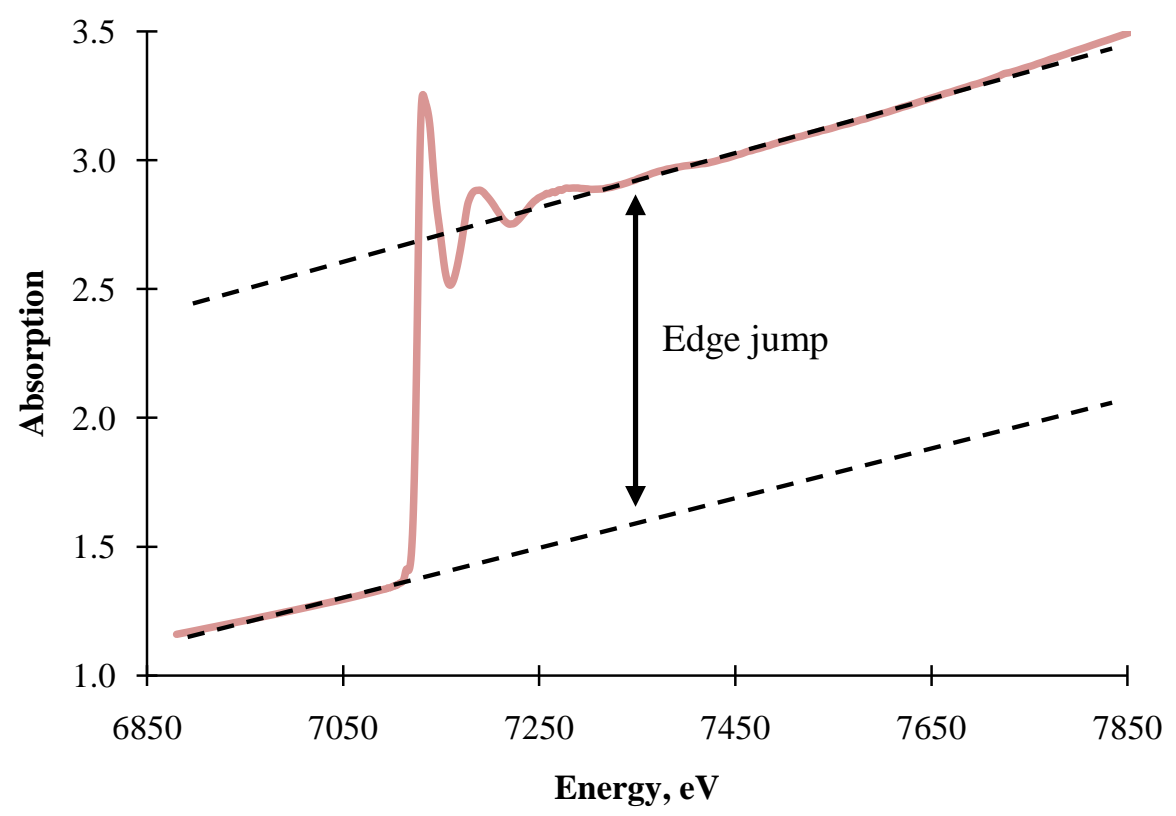

Figure 1: The edge jump corresponds to the total amount of the element present over the energy range selected. It is determined by assigning a pre-edge and post-edge line (on non-normalized data) and calculating the distance between them. 
Table 1: The component fit fractions are rounded up to half a percent, and are within 1-2\% standard deviation. Total sum and $\mathrm{R}$ value are calculated for each location.

\begin{tabular}{|c|c|c|c|c|c|c|c|c|}
\hline Sample & $\begin{array}{l}\text { Edge } \\
\text { Jump }\end{array}$ & $\begin{array}{l}\text { Methionine } \\
\mathrm{C}_{5} \mathrm{H}_{11} \mathrm{NO}_{2} \mathrm{~S} \\
\end{array}$ & $\begin{array}{c}\text { Elemental } \\
\text { Sulfur } S_{8} \\
\end{array}$ & $\begin{array}{c}\text { Sulfoxide (adj) } \\
\text { R-S(=O)-R' }\end{array}$ & $\begin{array}{c}\text { Sulfonate } \\
\mathrm{RSO}_{2} \mathrm{O}^{-} \\
\end{array}$ & $\begin{array}{c}\text { Sulfate } \\
\mathrm{SO}_{4}{ }^{2-} \\
\end{array}$ & Sum & R-value \\
\hline $\mathrm{A}$ & 0.661 & 0.029 & 0.070 & 0.011 & 0.019 & 0.800 & 0.929 & 0.0113 \\
\hline B & 0.690 & 0.025 & 0.083 & 0.021 & 0.061 & 0.715 & 0.905 & 0.0077 \\
\hline $\mathrm{C}$ & 0.483 & 0.062 & 0.158 & 0.036 & - & 0.639 & 0.895 & 0.0067 \\
\hline $\mathrm{D}$ & 0.299 & 0.118 & 0.297 & 0.068 & - & 0.435 & 0.918 & 0.0028 \\
\hline $\mathrm{E}$ & 0.256 & 0.162 & 0.283 & 0.096 & 0.160 & 0.251 & 0.952 & 0.0016 \\
\hline $\mathrm{F}$ & 0.192 & 0.184 & 0.420 & 0.114 & 0.039 & 0.185 & 0.941 & 0.0008 \\
\hline G & 0.263 & 0.192 & 0.420 & 0.120 & 0.063 & 0.152 & 0.947 & 0.0013 \\
\hline $\mathrm{H}$ & 0.363 & 0.091 & 0.279 & 0.067 & 0.064 & 0.398 & 0.899 & 0.0035 \\
\hline I & 0.389 & 0.059 & 0.283 & 0.077 & 0.117 & 0.355 & 0.890 & 0.0087 \\
\hline $\mathrm{J}$ & 0.322 & 0.134 & 0.468 & 0.118 & 0.053 & 0.169 & 0.942 & 0.0010 \\
\hline $\mathrm{K}$ & 0.260 & 0.148 & 0.435 & 0.121 & 0.052 & 0.174 & 0.930 & 0.0014 \\
\hline $\mathrm{L}$ & 0.665 & 0.028 & 0.093 & 0.025 & 0.080 & 0.727 & 0.952 & 0.0077 \\
\hline M & 0.322 & 0.057 & 0.272 & 0.071 & 0.144 & 0.339 & 0.883 & 0.0044 \\
\hline $\mathrm{N}$ & 0.534 & 0.037 & 0.126 & 0.028 & 0.007 & 0.700 & 0.899 & 0.0067 \\
\hline $\mathrm{O}$ & 0.478 & 0.039 & 0.175 & 0.037 & 0.063 & 0.615 & 0.929 & 0.0060 \\
\hline
\end{tabular}




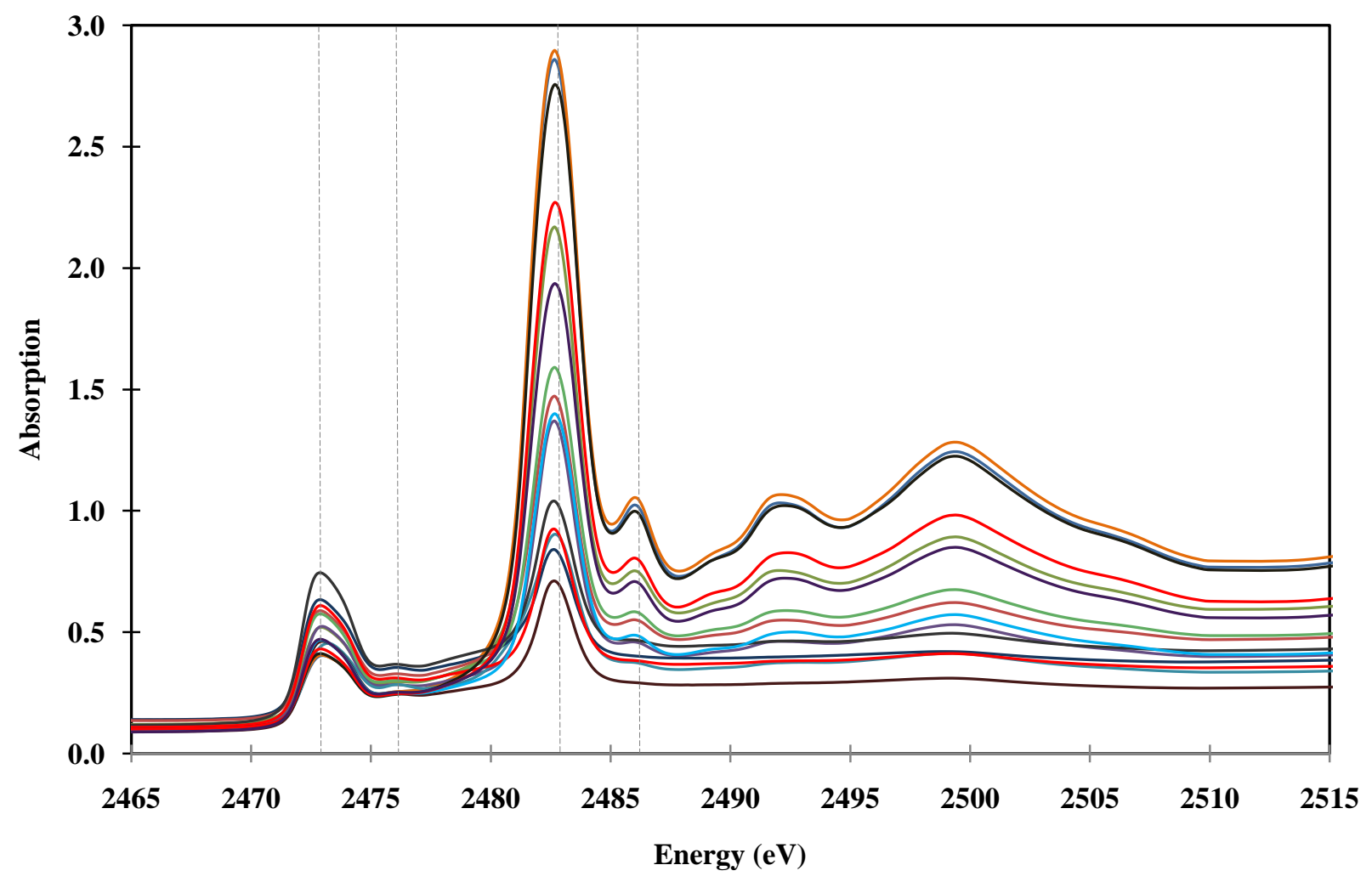

Figure 2: The fifteen XAS (absorption vs energy) spectra overlay. This data has not been normalized. The first peak occurs at $2472.96 \mathrm{eV}$, the second larger peak occurs at $2482.60 \mathrm{eV}$. Between them is a small feature near the oxidation state of sulfoxide. The features at energies greater than the peak at $2482 \mathrm{eV}$ indicate the presence of an ordered sulfate. 


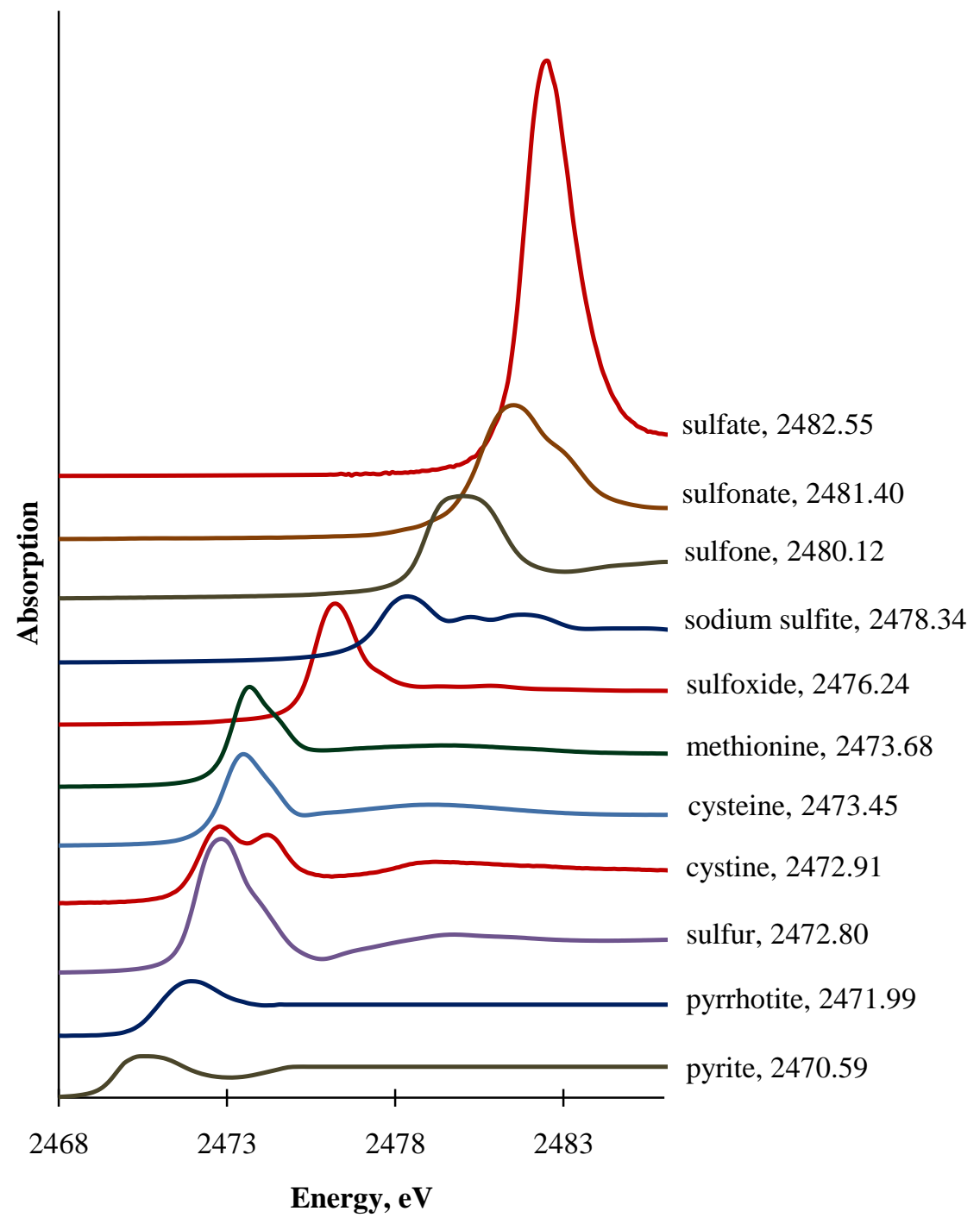

Figure 3: The library of reference spectra. These spectra were staggered vertically to better observe the peak energy differences. 
Table 2: The normalized proportions of sulfur species at each location calculated by multiplying the fit fraction of each species by the total amount of sulfur (edge jump).

\begin{tabular}{|c|c|c|c|c|c|}
\hline Sample & $\begin{array}{l}\text { Methionine } \\
\mathrm{C}_{5} \mathrm{H}_{11} \mathrm{NO}_{2} \mathrm{~S}\end{array}$ & $\begin{array}{c}\text { Elemental } \\
\text { Sulfur } S_{8}\end{array}$ & $\begin{array}{c}\text { Sulfoxide } \\
\text { R-S(=O)-R' }\end{array}$ & $\begin{array}{l}\text { Sulfonate } \\
\mathrm{RSO}_{2} \mathrm{O}^{-}\end{array}$ & $\begin{array}{c}\text { Sulfate } \\
\mathrm{SO}_{4}{ }^{2-}\end{array}$ \\
\hline A & 0.0189 & 0.0461 & 0.0073 & 0.0127 & 0.5287 \\
\hline B & 0.0172 & 0.0574 & 0.0146 & 0.0419 & 0.4931 \\
\hline $\mathrm{C}$ & 0.0300 & 0.0764 & 0.0174 & - & 0.3088 \\
\hline $\mathrm{D}$ & 0.0352 & 0.0888 & 0.0203 & - & 0.1301 \\
\hline $\mathrm{E}$ & 0.0415 & 0.0723 & 0.0247 & 0.0409 & 0.0641 \\
\hline $\mathrm{F}$ & 0.0352 & 0.0804 & 0.0218 & 0.0074 & 0.0354 \\
\hline $\mathrm{G}$ & 0.0505 & 0.1105 & 0.0314 & 0.0165 & 0.0400 \\
\hline $\mathrm{H}$ & 0.0331 & 0.1011 & 0.0244 & 0.0233 & 0.1442 \\
\hline I & 0.0231 & 0.1100 & 0.0300 & 0.0454 & 0.1379 \\
\hline $\mathrm{J}$ & 0.0432 & 0.1507 & 0.0382 & 0.0170 & 0.0545 \\
\hline $\mathrm{K}$ & 0.0383 & 0.1129 & 0.0315 & 0.0134 & 0.0453 \\
\hline $\mathrm{L}$ & 0.0184 & 0.0616 & 0.0169 & 0.0531 & 0.4829 \\
\hline $\mathrm{M}$ & 0.0184 & 0.0876 & 0.0230 & 0.0463 & 0.1091 \\
\hline $\mathrm{N}$ & 0.0198 & 0.0675 & 0.0152 & 0.0037 & 0.3737 \\
\hline $\mathrm{O}$ & 0.0184 & 0.0838 & 0.0178 & 0.0301 & 0.2940 \\
\hline
\end{tabular}



Figure 4: The normalized sulfate content compared to the overall sulfur content. As total sulfur increases, the sulfate content is observed to increase as well. 